\title{
Elderly Sexual Abuse in Residential Homes: Issues of Concern
}

ISSN: 2578-0093

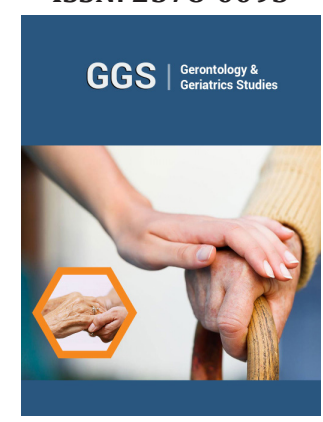

*Corresponding author: Virginia Miller, University of Charles Sturt, Canberra, Australia

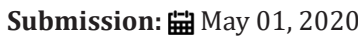

Published: 海 May 15, 2020

Volume 6 - Issue 1

How to cite this article: Virginia Miller, Bruce Stevens. Elderly Sexual Abuse in Residential Homes: Issues of Concern. Gerontol \& Geriatric stud. 6(1). GGS.000627. 2020.

DOI: $10.31031 /$ GGS.2020.06.000627

Copyright@ Virginia Miller, This article is distributed under the terms of the Creative Commons Attribution 4.0 International License, which permits unrestricted use and redistribution provided that the original author and source are credited.

\author{
Virginia Miller* and Bruce Stevens \\ University of Charles Sturt, Canberra, Australia
}

\section{Introduction}

This paper identifies issues of concern in relation to sexual abuse of elders in all agedcare residential homes and issues of concern that are most pertinent to faith-based agedcare facilities. However, the conflict of the rights of residents and, at times, competing rights and the moral values of the staff that care for them is not strictly an issue that is solely of concern to faith-based aged-care facilities. The most pressing issue is cognitive impairment especially as it relates to consent, but also as far as it relates to changes in sexual appetite and the vulnerabilities of people with cognitive impairment. These issues arising from cognitive impairment are discussed along with the rights of residents in nursing homes to increased freedoms, including sexual freedoms. We note that someone living in a residential home is generally considered to have the same rights as a person living in his or her own home. That said, unlike in their own homes, residential care health professionals and care-workers are tasked not only with ensuring that residents are free to exercise their freedoms, but also with ensuring that residents are free from sexual molestation. These already difficult tasks are made more difficult because of the working conditions in most aged-care facilities, e.g. staff have onerous workloads. It is argued below that care-workers in facilities who consider their work to be a vocation or 'calling' are more resilient in the face of poor working conditions. However, these care-workers are often conflicted in settings in which legislation has increased the freedoms of residents in aged-care facilities and diminished the rights of workers in faithbased aged-care facilities. For instance, a Catholic nursing home in Belgium was fined for refusing to allow a patient to access euthanasia services. In relation to sexual freedoms a careworker in a faith-based residential facility may have to prepare a patient for an adulterous sexual encounter, despite this practice being contrary to the values of the care-worker and the host institution ${ }^{1}$.

There have been numerous recommendations regarding elder sexual abuse and changes in aged-care facilities, including, but not limited to, ensuring that facilities have workable and up-to-date internal policies and procedures and that staff are trained in these policies and procedures. This paper is focused on aged-care in residential care in Australia, particularly, in light of the current Royal Commission into Aged-Care in Australia (Royal Commission into Aged-Care Quality and Safety). However, the findings in this paper are also relevant to agedcare facilities in other countries given that elder sexual abuse and matters of consent are global issues. Much of the academic literature in this paper refers to aged care in the UK and USA while the discussion of particular legal acts is focused on the Australian context.

\section{Definition}

There is a lack of clarity in the statistics concerning elderly sexual abuse in residential homes. In the USA it is claimed that less than $1 \%$ of all claims of abuse of elders in residential homes substantiated by the Adult Protective Services concern sexual abuse [1]. In the literature concerning elderly sexual abuse in residential homes, generally, it is claimed that

${ }^{1}$ Simon Caldwell, "Catholic care home in Belgium fined for refusing euthanasia”, Catholic Herald, $4^{\text {th }}$ July, 2016. Accessed 13/1/2020. https://catholicherald.co.uk/news/2016/07/04/catholic-care-home-inbelgium-fined-for-refusing-euthanasia/ 
between $1.8 \%$ and $17.5 \%$ of residents are victims of sexual abuse [2]. We note, the variation in these numbers is attributed in part to difficulties in the application of the definition of sexual abuse. Sexual abuse is broadly defined in the literature as unwanted sexual attention or exploitation and includes cases where a person who is the subject of sexual attention is not able to give consent due to cognitive impairment [3]. Here we do not want to conflate cognitive impairment and inability to provide consent. There are certainly situations where there is cognitive impairment and a preserved ability to provide consent. Moreover, given the heterogeneity of neurodegenerative disorders, there can be task-specific capacities even with progression of cognitive impairment. Therefore, cognitive impairment does not equal global incapacity. Thus, when we speak of cognitive impairment and the problem of consent, we are concerned with cognitive impairment that renders a person unable to provide consent.

This definition includes cases where a person with cognitive impairment initiates the sexual activity and cases where one spouse in a marriage has cognitive impairment. In Australia, unlawful sexual contact refers to non-consensual sexual contact [4]. However, the Aged Care Act 1997 (subsection 63-1AA (2)) in Australia does allow for care providers to make discretionary decisions regarding activities that are legally defined as sexual abuse if the person who committed the abuse has cognitive impairment. For instance, in the Act an approved provider must report to the police and to the Secretary allegations of/or reasonable suspicions of a reportable assault within 24 hours unless, within 24 hours after receiving the allegation or forming the suspicion, the approved provider believes that the assault was committed by a resident who had been assessed as suffering from cognitive impairment. If the case is not reported the care provider must arrange to manage the behavior of the resident, have documentation of the resident's cognitive impairment and a record of arrangements to manage the president's behavior (Subsection 63-1AA (3)). Despite the merits of this Act, including the consideration that residents with cognitive impairment are not subject to criminal charges for minor, possibly unintentional, sexual offences, this Act is not without criticism. For example, the Australian Law Reform Commission 2017 report, Elder Abuse-a National Legal Response (ALRC report) is critical of the measures that are outlined in this Act. It argues that the exemption of resident-on-resident violence is problematic. Thus, the ALRC report and the Review of National Aged Care Quality Regulation Processes Report (the Carnell-Paterson Review) recommend that a new Serious Incident Report Scheme (SIRS) be implemented. The Australian Government announced in the 2018-19 Budget that it would develop options for a SIRS, in consultation with the aged care sector [5]. Furthermore, at the time of writing, there is increased scrutiny on the aged-care sector including increased pressure to report on procedures due to the investigation of the Australian Royal Commission into Aged Care Quality and Safety. Sexual abuse has been flagged as an area of interest to the Commission, although, it does not have much to say on the matter in the interim report. Notwithstanding this, the Commission remark that the central purpose of the Final Report, which is yet to come, will be a complete overhaul of the aged-care sector including recommendations that concern objective, design, regulations, and funding [6].

\section{Victims of Abuse}

Victims of sexual abuse in aged-care facilities are predominantly women. For example, studies in the USA have found that 93.5-95\% of all reported cases of elder sexual abuse are women. The typical victim is a woman who is cognitively impaired and physically impaired [7]. The considerable impact of sexual abuse suffered by elderly victims is well-documented. For instance, older victims of rape are more likely than younger victims to be physically harmed because of their degenerative state, i.e. older women are more inclined to genital tears, have a greater susceptibility to contracting STDs, and to incur broken bones in the course of being sexually abused. Furthermore, there may be significant psychological, emotional, and behavioral harms suffered by victims of elder sexual abuse that are exacerbated by the victim's frail state and as a consequence of cumulative trauma experienced over the victim's lifetime [8].

\section{Perpetrators}

Perpetrators of sexual abuse in aged-care facilities may be fellow residents, spouses [9], aged-care workers and/or visitors (e.g. workmen, family or friends of residents). However, perpetrators are more likely to be residents than non-residents [9]. As such, it is likely that perpetrators have a relationship with the victims and with staff. Perpetrators, that are aware of their actions, and therefore morally culpable, are typical of sexual offenders in general. For instance, they are opportunistic, seek sexual gratification, and are angry and vindictive. Vindictiveness is evident in perpetrators who abuse women out of a generalized anger towards women [10]. We note that most perpetrators are men.

Perpetrators, who are care-workers, may be manipulative and gain the trust of supervisors, other workers, and residents. They are often well-liked by staff who mistake the perpetrator's tactics for creating opportunities to be alone with vulnerable residents as good work ethics on the part of the perpetrator. For instance, perpetrators may volunteer for undesirable tasks such as extra duties, night shift, and working with the most difficult residents [9]. Furthermore, and of interest to religious institutions, perpetrators may also be men who have been transferred to an old-aged facility because they have previously molested children. There is now evidence to suggest that many men who abuse children will also abuse adults [11].

\section{Risk Factors}

A range of factors put elderly residents at risk of sexual abuse in residential homes. Risk factors concerning staff problems include poor training; a lack of qualifications; the incorrect application of legislation; significant stress; negative attitudes towards older people; low frustration threshold and staff burnout [12]. Furthermore, a risk factor for all areas of abuse in aged-care, including sexual abuse, is low-paid staff. Paying competitive rates of pay ensures that the best staff can be obtained by a facility and that the staff are satisfied with their work and feel well-compensated. 
Risk factors for residents who are at risk of abusing other residents or staff include the following: cognitive impairment; psychiatric illness or psychological problems; loneliness; alcohol abuse; personality traits such as a blaming personality style and anti-social personality [13]. Furthermore, perpetrators may have a history of sexual offenses, but staff may not realize they pose a present danger to other residents, due to residents' advanced age and/or possible physical impairment [9]. Risk factors pertaining to elderly residents who are at risk of being the victim of sexual abuse, generally speaking, include cognitive impairment, a dependence on assisted daily living, psychiatric illness or psychological problems, poor physical health or frailty, low income or wealth, trauma, ethnicity, loneliness, alcohol use, incontinence and having no regular doctor [13]. Risk factors pertaining to social outlooks include sexism, paternalism in contexts of power inequality, and ageism [10].

\section{Cognitive Impairment}

A discussion of cognitive impairment is important stage-setting for this paper for the following reasons: (1) cognitive impairment can change a person's sexual habits; (2) people with cognitive impairment may not be judged competent to consent to sexual activity; (3) cognitive impairment can impede investigations into sexual abuse claims, and; (4) cognitive impairment can cause the people affected by it to have delusions, including reporting alleged sexual abuse.

Conditions that cause cognitive impairment, such as dementia in its various forms, can cause changes in the brain which can affect sexual behavior. Changes in sexual behavior associated with dementia may include, difficulties in maintaining personal boundaries, an increased or decreased interest in sex, a change in sexual style, i.e. a resident may become sexually aggressive, changes in sexual inhibitions, seemingly inappropriate behavior such as lewd behavior, public sexual expression, urges for immediate gratification, and risk-taking sexual behavior. A resident who behaves inappropriately may not know that his or her behavior is inappropriate and may be harmed by the behavior. For example, a resident who masturbates in public because he or she does not know that he or she is not in a private room may become distressed by the disapproval of those who witness the activity [14]. Residents with dementia may also get into bed with other residents who are mistakenly believed to be the resident's spouse or lover [7].

There is considerable debate regarding whether or not a person with significant cognitive impairment is able to competently make important decisions that may, if the wrong decision is made, have significant negative consequences. Here, we re-iterate that a diagnosis of dementia or cognitive impairment does not suggest there is global incapacity. However, for the purposes of this paper we have limited our discussion to those forms and degrees of cognitive impairment which limit a person's ability to make decisions relating to sexual activity and what is in their best interests. The decisions which are of interest to this discussion concern sexual activity, particularly sexual activity that is potentially significantly harmful. For instance, it is generally agreed that there is no intervention required if a married couple (with one or both spouses affected by cognitive impairment) wish to hold hands and cuddle, but what about consenting to unprotected sex with another resident who may not be the resident's spouse? Clearly, complex decisions with potentially harmful consequences require greater mental ability. It has been argued that every sexual encounter with potentially harmful consequences needs an assessment to ensure that nobody is being harmed [15]. We note here that this practice does not unjustly discriminate against people with cognitive impairment nor hold them to a higher standard, given that people in general are allowed to make decisions with potentially harmful consequences. On the contrary, this practice protects people with cognitive impairment from the harmful effects of an impaired judgement process and also aids care-staff to protect other residents from molestation.

A further concern arises in relation to evidence gathering from victims of sexual abuse who have a cognitive impairment. For instance, cognitive impairment may impede an investigation into sexual abuse as the victim may not be able to give a clear account of the abuse. Some residents are unable to communicate effectively due to conditions that restrict communication such as aphasia, advanced dementia, profound developmental disabilities, or loss of consciousness. Furthermore, residents who do not have difficulty communicating due to a physiological problem may have a difficulty related to a mental health problem such as paranoia and active psychosis [9]. In other cases, usually when there is severe dementia, the victim may not even know that she has been abused [7]. Lastly, cognitive impairment can also lead residents to make false claims of sexual abuse. For example, actions performed by care-workers on elders with cognitive impairment, such as routine hygiene by care-staff, may be interpreted as sexually motivated by the residents [7].

\section{Increased Freedoms}

It is generally considered that someone living in a residential setting is living 'in their own home'. In other words, residents in aged-care facilities have the same rights to live the life they wish to live as other people who are not in aged-care facilities, assuming that their rights have not been curtailed by law, as may be the case with people with cognitive impairment. Importantly, the life an elderly person chooses to live may appear to be unwise or immoral from another person's point of view (Heath, 2011, 16). Consequently, much has been written concerning the rights of residents in aged-care facilities. In Australia, the Charter of Aged Care Rights supports the following rights of elderly residents in aged-care facilities: (1) the right to have control over and make choices about care, and personal and social life, including where the choices involve personal risk; (2) the right to have control over and make decisions about, the personal aspects of daily life, financial affairs and possessions; (3) the right to independence; and (4) the right to exercise these rights without it adversely affecting treatment (Australian Department of Health).

In light of all four of these rights, sexual expression is a right of elderly residents in aged-care facilities, if they can consent 
to sexual activity. Moreover, it has, otherwise, been argued that intimacy and sexual expression can contribute to the health and wellbeing of the elderly [14]. For instance, elderly people with an active sex life report a greater degree of satisfaction with the quality of their lives. However, the positive aspects of sexuality in the elderly must be considered alongside the knowledge that various forms of sexual expression, e.g. resident-to-resident sexual aggression, negatively affects a person's quality of life, health and wellbeing [7]. Therefore, the weighing up of freedoms and potential harms are important when it comes to assessing sexual activity in residential homes. This is particularly important with residents who have cognitive impairment and, therefore, may not be legally competent to consent to sexual activity. The tension between the right of elderly residents to engage in sexual activity and policies that protect residents with cognitive impairment are described by Alex Ruck Keene, who is a barrister specializing in mental capacity, as a clash between 'two competing policy goals-both absolutely laudable and absolutely incompatible' [16]. Here, we note that the court is not in a position to determine if somebody is competent to consent to sexual activity. Therefore, health professionals and care workers in aged-care facilities are tasked with the complicated job of evaluating the capacity of patients with cognitive impairment to consent to sexual activity.

\section{Assessing capacity to consent to sex}

It is worth pointing out here that there is no clear consensus regarding how to determine the existence of the capacity of a person to give sexual consent and there are different models to discern whether or not consent has been given. In all cases it is necessary to establish that the resident understands the sexual nature of the act, that the act is voluntary, and that the resident understands the potential consequences of that sexual conduct. Harmful consequences of elder sexual behavior include STD's, physical harm, and also social disapproval. In many cases it is also important for the resident to understand the moral quality of the sexual conduct. For example, the moral quality standard requires the resident to understand the social mores of the sexual behavior [17].

The issue of consent is further complicated by the many variables in sexual activity. For instance, a person may be considered to be capable of deciding to engage in one form of sexual expression but not another. Or, a person may be found to be capable to make a decision to engage in sexual activity at one time but not at another time [17]. Hence, the popularity of the Case-by-Case Basis model of determining consent. In this model institutions evaluate the residents' capacity to consent to sexual activity on a case-bycase basis. For instance, healthcare professionals evaluate each individual and the facts specific to his or her situation in order to reach a conclusion as to whether or not the individual is capable of consenting to sexual activity. Another proposed solution is to give an individual's guardian the right to consent on behalf of the individual with dementia [17]. However, this idea is controversial. In general, it is argued that care-workers should presume consent between those nursing home residents who, prior to becoming cognitively impaired, had consented over many years to have sex with one another, even if the individual(s) may not now legally have the capacity to give it.

The means by which people with cognitive impairment consent to sexual expression is an area of unclarity without a settled policy. Take for instance the following quote, 'Even an Alzheimer's patient who has lost the ability to talk can express desire or dismay through sounds, facial expressions, and hand gestures' [17]. It is Melissa White's view that care-staff should be able to interpret these nonverbal gestures and expressions for consent. 'Nursing home staff must be observant of the resident behavior to prevent and put a stop to any sexual abuse while still respecting the residents' desires for intimacy' [17]. Yet, as she mentions, there are potentially harmful consequences if the staff misinterprets consent; specifically, a person may well be sexually abused. Furthermore, staff are riskaverse because of the potential for lawsuits in these situations [17].

\section{Staff Issues}

Care staff are responsible for ensuring that elders have sexual freedom while also protecting elders from sexual abuse. Often care staff are called to negotiate the interests of residents and their families, staff, and regulatory bodies despite having minimal training to do so. For instance, in Australia it is generally required, but not mandatory, that care staff have a Cert III from Technical and Further Education (TAFE). Furthermore, care-staff are called upon to discern whether or not sexual activity is consensual and are expected to notice the potential signs of sexual abuse. For instance, an often-quoted scenario concerns staff failing to recognize that a woman in residential care wearing multiple layers of clothing was trying to protect herself from further sexual abuse from another resident. It is argued that care staff need to be trained to see these signs including, discerning whether an allegation is true or a case of deluded thinking [9]. Furthermore, care staff may be called upon to treat victims who have been the victim of sexual abuse all the while ensuring that evidence is not contaminated. Nurses are also called upon to investigate claims of sexual abuse and make discretionary determinations in some of these cases if they involve a person with cognitive impairment. Care staff may also find themselves in the invidious position of providing care to sexual assault victims and to residents who have sexually offended [9].

Generally, increased sexual freedom in residential homes is a fraught topic for care-workers. For example, one care-worker said, 'while you assist residents who need help with hygiene before and after meals, using the lavatory or episodes of incontinence, do you help the resident with hygiene before and after sexual activity? In your everyday work do you follow infection control procedures in order to protect yourself and others from infections which can be related to sexual activity, such as HIV?' (Heath, 2011, 18). Generally, employment conditions for care-workers are poor, e.g. onerous workloads, inadequate staffing ratios, inadequate training and low pay [10]. Consequently, there are a lack of people who are prepared to accept these conditions and those who do often move from one workplace to another. Because of a lack of available care-staff residential homes are often prepared to employ care-staff without quality references and police checks. It has been argued that a 
better quality of care is provided by care-staff who view their work as vocational i.e. as a religious 'calling'.

\section{Issues Specific to Religious Institutions}

The vocational aspect of nursing is most apparent in the writings of Florence Nightingale who developed a system of nursing that focused on the vocational aspect of the caring profession. The definition of nursing in Judith [18] book, Called to Care: A Christian Worldview of Nursing, is helpful here, 'we will define Christian nursing as a ministry of compassionate care for the whole person, in response to God's grace toward a sinful world, which aims to foster optimum health (shalom) and bring comfort in suffering and death for anyone in need' (17). Faith and religious ethics are not only of importance to care-workers but also to the residents themselves. In the World Health Organization (WHO) report on the prevention of elder abuse it is reported that elders with strong religious beliefs were better able to withstand the negative effects of sexual abuse [12].

Yet, nurses who view their profession as a calling are confronted more often than not with a market-based model of nursing, even in religious organizations, leading to dissatisfaction and a sense that they are under-appreciated. Furthermore, there are difficulties for staff with religious convictions, especially with legislation for increased freedoms of residents and diminishing religious freedoms for workers, even in religious organizations. Careworkers are asked to accept adulterous relationships, pornography, and sex-workers, as these are seen to be freedoms that should be available to residents in aged-care facilities. However, a difficulty arises here as care workers may have to facilitate behavior which is contrary to their religious beliefs. For instance, a care worker may be under pressure to arrange a sex-worker for a resident despite the care-worker finding this to be a morally reprehensible type of behavior. We note here that the leading magazine in Australia on issues related to aged-care, Aged Care Insite, recently ran an article supporting sex workers who specialize in sex work to seniors, in and outside of residential care. Moreover, here there is potentially a conflict between regulations that encourage sexual freedoms and codes of conduct that care-workers who are considered church workers are expected to comply with, e.g. Faithfulness in Service [19] prohibits engaging in prostitution (31).

\section{Currently Doing/Recommendations}

Recommendations that have been made in research reports and government reports regarding elder sexual abuse in residential homes include the following: facilities need to ensure that they have workable and up-to-date internal policies and procedures and staff training in their policies and procedures; facilities need to adopt screening programs for staff selection; facilities must embed ethical codes of conduct; facilities must encourage mandatory reporting; facilities need to ensure wider inter-sectoral collaboration e.g. police, GPs and community health sectors; facilities need to create strategies based in technology and design; facilities need to improve staff ratios; facilities need to increase rates of pay for carestaff [10] facilities need to create a culture of reporting, responding and documenting alleged or suspected assaults; and facilities need to train staff to recognize if an assault has occurred and how to respond' [20]. Furthermore, facilities need to ensure that full background checks are undertaken for all staff working in agedcare facilities ${ }^{2}$.

Clearly there is much work which has been done and is currently being undertaken to reduce sexual abuse in residential care. Moreover, the ongoing work of the Australian Royal Commission will certainly effect considerable change in the agedcare sector of Australia. However, much of the discussion thus far has not considered the two primary issues in this paper concerning increased sexual freedoms of residents in aged-care facilities: (1) how can consent be reasonably determined in all cases where a person has cognitive impairment? And; (2) how are the increased sexual freedoms of residents in aged-care facilities weighed against the freedoms of care-workers? In relation to the first question we mentioned that a barrister specializing in mental capacity found policies concerning increased sexual freedoms and regulations to protect elderly residents from molestation to be incompatible. We might then imagine that a low-skilled care-worker to be in less of a position to navigate these competing policies. Clearly, there is room for further research regarding the difficulties encountered by carestaff enacting government policies [21-23].

Regarding the second point, it is recommended that faith-based aged-care facilities ensure that aged-care meets the requirements of religious ministry. Notably, the vocational nature of care must be emphasized and fostered in a spiritually formative way. Staff must not feel that their religious values are compromised in their vocation. Similarly, the freedoms of elderly residents must also be weighted alongside religious values, in faith-based institutions. Moreover, the spiritual formation of elderly residents must not be undervalued. Indeed, recent recommendations of the Australian Royal Commission are compatible with faith-based values. For instance, the Royal Commission strongly recommends that agedcare must move away from market-based and, so-called, consumerbased models into what the Royal Commission consider relationship models of aged-care that are concerned with fostering meaningful relationships between all interested parties. This fundamental mindset shift focuses on a style of care that is beneficial for all involved. It encourages the participation of residents and their families in the style of care they receive and encourages care-staff to also assert their own needs. This style of care should be second nature to faith-based organizations who, by their very nature of being our communion and community based.

Moreover, secular institutions must consider the values and ethical commitments of their workers, especially as far as they relate to sexual mores. For instance, a care-worker in a secular institution

${ }^{2}$ Megan Tran, 'Sex Work in Aged Care More Than Just Physical' in, Aged Care Insite, August 13, 2018, https://www.agedcareinsite.com.au/2018/08/sexwork-in-aged-care-more-than-just-physical/ 
may not feel comfortable with the extreme sexual behavior of some residents. We have used religious-based institutions as a casestudy in this paper given that there is often a conflict of interest between public policies for increased freedoms of residents in aged-care facilities and restrictions concerning workers in religious organizations. However, the essence of this argument is relevant to secular institutions as well.

Source of Funding: This work was funded by Aged-Care Plus (Salvation Army, Australia)

\section{References}

1. Teaster PB, Otto JM, Dugar TD, Mendiondo MS, Abner EL, et al. (2006) The 2004 survey of state adult protective services: Abuse of adults 60 years of age and national center on elder abuse. Administration on Aging, Washington, USA.

2. Hayward L, Robertson N, Knight C (2012) Inappropriate sexual behavior and dementia: An exploration of staff experiences. Dementia 12 (4): 463-480.

3. http://www.nursinghomeabuseguide.org/

4. https://www.legislation.gov.au/Details/C2017C00241

5. Commonwealth Department of Health (2019) Strengthening protections for older Australians. Development of model and options for a serious incident response scheme (SIRS) for commonwealth funded aged care service providers.

6. Royal Commission into Aged Care Quality and Safety (2019) Interim Report: Neglect, Commonwealth of Australia, Volume: 1.

7. Rosen T, Mark SL, Pillemer K (2010) Sexual aggression between residents in nursing homes: literature synthesis of an underrecognized problem. Journal of the American Geriatrics Society 58(10): 1970-1979.

8. Furey EM, Niesen JJ, Strauch JD (2006) Abuse and neglect of adults with mental retardation in different residential settings. Behavioral Interventions 9(4): 199-211.

9. Klawsnik HR, Teaster P, Mendiondo M, Abner E, Cecil K, et al. (2007) Sexual Abuse of vulnerable adults in care facilities: clinical findings and a research initiative. Journal of the American Psychiatric Nurses Association 12(6): 332-339.
10. Mann R, Horsley P, Barrett C, Tinney J (2014) Norma's project. A research study into the sexual assault of older women in Australia. Australian Centre in Sex, Health and Society, La Trobe University, Melbourne, Australia.

11. Lea SJ, Hunt L, Shaw S (2010) sexual assault of older women by strangers. J Interpers Violence 26(11): 2303-2320.

12. Sethi D, Wood S, Mitis F, Bellis M, Penhale B, et al. (2011) European Report on Preventing Elder Maltreatment. World Health Organization Regional Office for Europe.

13. Johannesen M, LoGiudice D (2013) Elder abuse: a systematic review of risk factors in community-dwelling elders. Age and Ageing 42(3): 292298.

14. Tarzia L, Fetherstonhaugh D, Bauer M (2012) Dementia, sexuality and consent in residential aged care facilities. Journal of Medical Ethics $38(10)$.

15. Michael B, Fetherstonhaugh D (2016) Sexuality and people in residential care facilities: A guide for partners and families. Australian Centre for Evidence Based Aged Care (ACEBAC), La Trobe University, Australia.

16. Rix, Julia (2019) Sex and dementia: the intimate minefield of consent in a care home. The Guardian, UK.

17. White, Melissa C (2010-2011) The eternal flame: Capacity to consent to sexual behavior among nursing home residents. The Elder Law Journal 18: 133.

18. Allen JS, Miller AB (2006) Called to care: A Christian worldview for nursing. Illinois: InterVarcity Press, USA

19. The Anglican Church of Australia Trust (2017) Faithfulness in Service.

20. https://agedcare.health.gov.au/ensuring-quality/aged-care-qualityand-compliance/guide-for-reporting-reportable-assaults

21. https://agedcare.health.gov.au/quality/single-charter-of-aged-carerights

22. Simon C (2016) Catholic care home in Belgium fined for refusing euthanasia. Catholic Herald.

23. Megan T (2018) Sex work in aged care more than just physical. Aged Care Insite. 